\title{
Parathyroid hormone is associated with heart failure with preserved ejection fraction
}

\author{
Bezgin $\mathrm{T}^{1}$, Elveran $\mathrm{A}^{2}$, Karagoz $\mathrm{A}^{1}$, Canga $\mathrm{Y}^{3}$, Dogan $\mathrm{C}^{1}$ \\ Department of Cardiology, Kartal Kosuyolu Heart and Research Hospital, Istanbul, Turkey. \\ bezgintahir3@yahoo.com
}

\begin{abstract}
BACKGROUND: Parathyroid hormone (PTH) is a novel promising biomarker that can predict hospitalization, functional status and mortality in patients who suffered heart failure with preserved ejection fraction (HFpEF). OBJECTIVE: We aimed to investigate the association of serum PTH levels and measures of disease severity (NYHA functional class, NT-proBNP, CRP, EF, Troponin I) in patients with HFpEF.

METHODS: A total of consecutive 58 outpatients with HFpEF and 30 controls were prospectively studied. All patients underwent laboratory tests, including NT-proBNP and PTH analyses.

RESULTS: PTH, NT-proBNP, troponin I, and CRP levels were significantly higher in patients with HFpEF when compared with control group (54.61 \pm 31.02 vs $40.40 \pm 14.22 \mathrm{pg} / \mathrm{ml}, \mathrm{p}<0.05 ; 126.05 \pm 162.94$ vs $44.57 \pm 14.95$ $\mathrm{pg} / \mathrm{ml}, \mathrm{p}<0.01 ; 0.011 \pm 0.013$ vs $0.004 \pm 0.001 \mathrm{ug} / \mathrm{L}, \mathrm{p}<0.01 ; 4.65 \pm 4.24$ vs $1.63 \pm 0.97 \mathrm{mg} / \mathrm{L}, \mathrm{p}<0.01$, respectively). Left atrium was found to be more enlarged in HFpEF patients (LAVI = 36 $\pm 18 \mathrm{vs} 28 \pm 11 \mathrm{ml} / \mathrm{m}^{2}, \mathrm{p}$ $<0.01)$. Most indices of left ventricular diastolic function were more severely impaired compared to controls $(p$ $<0.05$ ). There was no correlation between PTH and CRP, troponin I, LVMI, LV volumes, LV diameters, E/E', age, and BMI in both groups ( $p=N S$ ). There was strong positive correlation between PTH and NT-proBNP levels in all study participants $(r=0.359 ; p<0.01)$.

CONCLUSION: PTH together with other markers of heart failure may provide valuable information both in the diagnosis and staging of heart failure syndromes (Tab. 4, Fig. 1, Ref. 40). Text in PDF www.elis.sk.

KEY WORDS: parathyroid hormone, preserved ejection fraction, heart failure.
\end{abstract}

\section{Introduction}

Heart failure with preserved ejection fraction (HFpEF) is a common and increasing public health issue related with significant morbidity and mortality. HFpEF currently accounts for $\geq 50$ $\%$ of the general heart failure population, and its 1 - and 5 -year survival rates are similar to or only slightly better than those of patients with reduced ejection fraction (HFrEF) (1-4). The diagnosis of HFpEF requires the following four criteria to be fulfilled: (i) presence of signs or (ii) symptoms of heart failure; (iii) normal or near normal systolic function (EF $\geq 50 \%$ ) and LV not dilated; and (iv) relevant structural heart disease (LV hypertrophy/ LA enlargement) and/or diastolic dysfunction (4). Impairment in left ventricular (LV) diastolic function related with myocardial hypertrophy and fibrosis has been proposed as a key pathophysiologic mediator. Noninvasive estimation of LV filling pressures is a clinical requisite to make the diagnosis of diastolic dysfunction (5).

\footnotetext{
${ }^{1}$ Department of Cardiology, Kartal Kosuyolu Heart and Research Hospital, Istanbul, ${ }^{2}$ Darica Farabi State Hospital, Cardiology Clinic, Darica-Gebze/ Kocaeli, and ${ }^{3}$ Department of Cardiology, Siyami Ersek Cardiothoracic and Vascular Surgery Center, Istanbul, Turkey

Address for correspondence: T. Bezgin, MD, Kartal Kosuyolu Heart Research Hospital Denizer Cad. Cevizli 34846, Kartal-Istanbul, Turkey. Phone: +90.505.4424712, Fax: +90.216.4596321
}

Parathyroid hormone (PTH) which is responsible for calcium homeostasis is an independent predictor of severity, prognosis and need for hospitalization in patients with $\operatorname{HFrEF}(6,7)$. Several factors including hypovitaminosis D, aldosteronism, chronic use of furosemide and impaired renal function have been shown to contribute to the appearance of secondary hyperparathyroidism in HF patients (8) (Fig. 1).

PTH was demonstrated to be a pro-hypertrophic factor by increasing protein synthesis in vitro. Cardiomyocytes were reported to be targets of PTH $(9,10)$. A significant association was demonstrated between LV mass and PTH level both in healthy population (11) and patients with different diseases $(12,13)$.

We aimed to investigate the association of serum PTH levels and measures of disease severity (NYHA functional class, NTproBNP, CRP, EF, troponin I) in patients with HFpEF. Also we searched for the relationship between PTH levels and diastolic parameters in patients with preserved systolic function.

\section{Method}

Following the obtaining of informed consent for the study, all patients underwent a comprehensive echocardiographic examination. We prospectively enrolled 60 patients who met the diagnostic clinical heart failure criteria and 30 controls. Demographic data including age, gender, body mass index (BMI), body surface area 


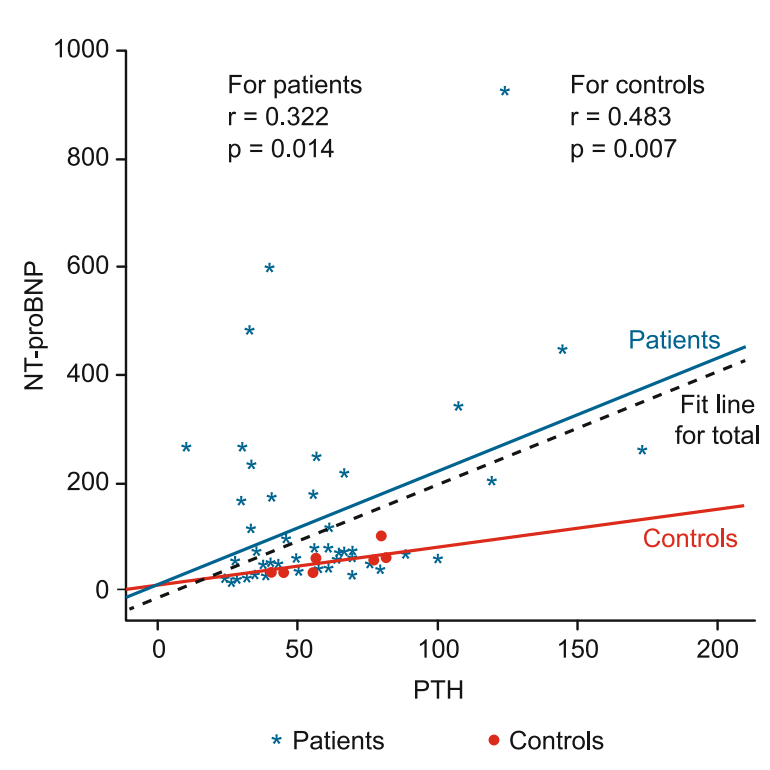

Fig. 1. Relationship between parathyroid hormone and NT-proBNP in patients with HFpEF and control group.

(BSA) and comprehensive clinical data including history of hypertension, diabetes mellitus, dyslipidemia, history of smoking, coronary artery disease, peripheral arterial disease, history of prior myocardial infarction and coronary artery bypass surgery were collected. Systolic and diastolic blood pressures were measured at the time of echocardiographic exam.

Exclusion criteria for the study were chronic renal failure (creatinine clearance $<90 \mathrm{ml} / \mathrm{min} / 1.7 \mathrm{~m}^{2}$ ), long- term alcoholism, pancreatitis, primary hyperparathyroidism, malignancy, liver disease and spironolacton use.

All patients had signs and symptoms of heart failure, and a normal or near normal ejection fraction (LVEF $\geq 50 \%$ ), non-dilated LV cavity and associated structural heart disease and/or left atrial enlargement and/or LV diastolic dysfunction as stated in the ESC guidelines for heart failure (4). The study participants were divided into 4 functional groups based on NYHA class. Anemia was defined as hemoglobin level $<13 \mathrm{~g} / \mathrm{dl}$ in men and $<12 \mathrm{~g} / \mathrm{dl}$ in women in accordance with World Health Organization criteria. Hypertension was defined as blood pressure $>140 / 90 \mathrm{mmHg}$ on $>2$ occasions during office measurement or on antihypertensive drug.

Comprehensive laboratory tests, including measurements of NT-proBNP, PTH and troponin I levels were performed. NTproBNP levels were measured using an enzyme immunoassay technique. The established normal range for NT-proBNP assay was: $0-125 \mathrm{pg} / \mathrm{ml}$ for ages $2-74 ; 0-450 \mathrm{pg} / \mathrm{ml}$ for ages $>75$. The established normal range for PTH and troponin I were $15-65 \mathrm{pg} /$ $\mathrm{ml}$ and $0-0.014 \mathrm{ug} / \mathrm{L}$, respectively. PTH level was measured by using Cobas e 601(Roche Diagnostics, Germany) analyzer with electrochemiluminescence immunoassay (ECLIA) method. CRP levels were calculated (normal range: $0-5 \mathrm{mg} / \mathrm{L}$ ) by using Cobas e 601 (Roche Diagnostics, Germany) analyzer with immunoturbidimetric method.

\section{Echocardiographic assessment}

All participants underwent a complete transthoracic echocardiography according to the American Society of Echocardiography guidelines (14) by one operator, who was blinded to the clinical and laboratory results of the study group. Transthoracic echocardiographic studies were carried out with the patient in the left lateral position using a GE Vivid 7 system (GE, Horten, Norway) with a 3.5-MHz transducer. All data were transferred to a workstation for further offline analysis (EchoPAC-PC v7.1,2; GE Vingmed Ultrasound AS, Horten, Nor- way). LV internal dimensions (enddiastolic LV diameter and end-systolic LV diameter) and wall thickness of the ventricular septum and posterior wall were measured from two-dimensional (2D-guided) M-mode echocardiographic tracings obtained at the mid-chordal level of the parasternal long axis. LV end-diastolic and end-systolic volumes and EF were measured in apical two-chamber (2C) and four-chamber views. LA volume $(\mathrm{ml} / \mathrm{m} 2)$ was measured using the biplane area-length method and normalized for body surface area. The transmitral flow velocity was obtained from apical $4 \mathrm{C}$ view with the pulsed-wave Doppler method. After measuring the peak early (E) and late (A) diastolic velocities and deceleration time (DT), the ratio of early to

Tab. 1. The comparison of gender, age, and clinical characteristics of patients with heart failure with preserved ejection fraction vs control group.

\begin{tabular}{|c|c|c|c|}
\hline & $\begin{array}{l}\text { Patients with HFpEF } \\
(\mathrm{n}=58)(\text { mean } \pm \text { SD })\end{array}$ & $\begin{array}{c}\text { Control-group } \\
(\mathrm{n}=30)(\text { mean } \pm \mathrm{SD})\end{array}$ & $\mathrm{p}$ \\
\hline Age (years) & $62 \pm 9$ & $61 \pm 7$ & $\mathrm{a} 0.436 * *$ \\
\hline Body mass index $\left(\mathrm{kg} / \mathrm{m}^{2}\right)$ & $26.67 \pm 2.15$ & $25.40 \pm 1.40$ & $\mathrm{a} 0.001 * *$ \\
\hline Diastolic blood pressure $(\mathrm{mmHg})$ & $81.50 \pm 10.06$ & $76.03 \pm 12.79$ & $\mathrm{a} 0.031 *$ \\
\hline Systolic blood pressure (mmHg) & $150.59 \pm 22.94$ & $127.73 \pm 25.53$ & $\mathrm{a} 0.001 * *$ \\
\hline Heart rate (beat per minute) & $77.33 \pm 12.26$ & $79.33 \pm 12.75$ & $\mathrm{a} 0.475$ \\
\hline Sex (female ) & $30(51.7)$ & $14(50)$ & $\mathrm{c} 0.653$ \\
\hline Arterial hypertension & $27(46.6)$ & $6(20)$ & b0.027* \\
\hline Diabetes mellitus & $10(17.2)$ & $4(13.3)$ & $\mathrm{c} 0.764$ \\
\hline Smoking & $5(8.6)$ & $5(16.7)$ & c0.299 \\
\hline Hyperlipidemia & $11(19)$ & $3(10.0)$ & $\mathrm{c} 0.365$ \\
\hline Coronary artery disease & $5(8.6)$ & $1(3.3)$ & $\mathrm{c} 0.659$ \\
\hline
\end{tabular}

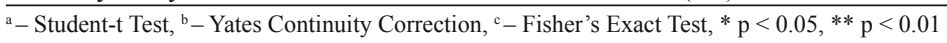


Tab. 2. The comparison of the biochemical parameters of patients with heart failure with preserved ejection fraction vs control group.

\begin{tabular}{lcc}
\hline & $\begin{array}{c}\text { Patients with HFpEF } \\
(\mathrm{n}=58)(\mathrm{Mean} \pm \mathrm{SD})\end{array}$ & $\begin{array}{c}\text { Control group } \\
(\mathrm{n}=30)(\mathrm{Mean} \pm \mathrm{SD})\end{array}$ \\
\hline Parathyroid hormone $(\mathrm{pg} / \mathrm{ml})$ & $54.61 \pm 31.02$ & $40.40 \pm 14.22$ \\
NT-proBNP (pg/ml) & $126.05 \pm 162.94$ & $44.57 \pm 14.95$ \\
Troponin I (ug/l) & $0.011 \pm 0.013$ & $0.004 \pm 0.001$ \\
CRP (mg/L) & $4.65 \pm 4.24$ & $1.63 \pm 0.97$ \\
Creatinine (mg/dl) & $1.13 \pm 1.37$ & $0.89 \pm 0.22$ \\
Hemoglobin (gr/dl) & $13.52 \pm 1.42$ & $13.10 \pm 1.42$ \\
Calcium (mg/dl) & $9.55 \pm 0.47$ & $9.82 \pm 0.72$ \\
Phosphrus (mg/dl) & $3.27 \pm 0.53$ & $3.45 \pm 0.40$ \\
LDL (mg/dl) & $132.24 \pm 32.06$ & $116.17 \pm 17.01$ \\
Glucose (mg/dl) & $107.43 \pm 39.28$ & $83.83 \pm 12.56$ \\
CRP - C-reactive protein; LDL - low density lipoprotein; NT-proBNP - N-terminal Pro-brain Natriuretic Peptide, ${ }^{\mathrm{a}}-$ Student-t Test
\end{tabular}
$\mathrm{p}<0.05, * * \mathrm{p}<0.01$

late diastolic mitral inflow velocities (E/A) was calculated. Mitral annulus velocities were obtained by using pulsed tissue Doppler imaging from the apical $4 \mathrm{C}$ view, by placing the sample volume at the junction of the LV wall with the septal mitral annulus, and recording at a sweep of $100 \mathrm{~mm} / \mathrm{s}$. Peak systolic (Sm), early (Em) and late diastolic (Am) annular velocities were obtained. The ratio of early diastolic mitral inflow velocity to early diastolic annular velocity $(\mathrm{E} / \mathrm{Em})$ was calculated. All measurements were carried out from three cardiac cycles and then averaged.

\section{Statistics}

We used NCSS (Number Cruncher Statistical System) 2007\&PASS (Power Analysis and Sample Size) 2008 Statistical Software (Utah, USA) to perform statistical analyses. When evaluating study data, beside descriptive statistic methods (mean, standard deviation, median, frequency, and ratio) Student t Test was used for comparison of continuous variables showing normal distribution. Mann-Whitney U test was used in comparison of 2 group parameters which did not distribute normally. Pearson $\mathrm{x}^{2}$ test and in case of detection of group causing difference, Fisher's Exact test and Yates Continuity Correction test were used to compare qualitative variables. Spearman correlation was used for cor- relation assessment between parameters. Significance was inferred with $\mathrm{p}$ values $<0,01$ and $\mathrm{p}<0.05$.

\section{Results}

Baseline characteristic and clinical data of study participants were demonstrated in Table 1. Age of patients with HFpEF and control group was comparable (62 \pm 9 vs $61 \pm 7$, respectively; p: NS). Body mass indices of patients with HFpEF were significantly higher compared to control group $(p<0$. 01). Similarly, both systolic and diastolic blood pressures in patients with HFpEF were detected to be higher than those in control group $(\mathrm{p}<0.05)$.

PTH levels were significantly higher in patients with HFpEF $(54.61 \pm 31.02$ vs $40.40 \pm 14.22 \mathrm{pg} / \mathrm{ml} ; \mathrm{p}<0.05)$ (Tab. 2). Also, NT-proBNP, troponin I and CRP levels were found to be significantly elevated in patients having HFpEF compared to control group $(126.05 \pm 162.94 \mathrm{vs} 44.57 \pm 14.95 \mathrm{pg} / \mathrm{ml} ; \mathrm{p}<0.01 ; 0.011 \pm$ 0.013 vs $0.004 \pm 0.001 \mathrm{ug} / \mathrm{L} ; \mathrm{p}<0.01 ; 4.65 \pm 4.24$ vs $1.63 \pm 0.97$ $\mathrm{mg} / \mathrm{L} ; \mathrm{p}<0.01$, respectively). Similarly, creatinine, calcium, and phosphorus levels were seen not to be different in patients with HFpEF compared to control group $(p>0.05)$. Both glucose and

Tab. 3. Two-dimensional and Doppler echocardiographic findings of patients with heart failure with preserved ejection fraction vs control group

\begin{tabular}{|c|c|c|c|c|}
\hline & & $\begin{array}{l}\text { Patients with HFpEF } \\
(\mathrm{n}=58)(\text { mean } \pm \text { SD })\end{array}$ & $\begin{array}{c}\text { Control group } \\
(\mathrm{n}=30)(\text { mean } \pm \mathrm{SD})\end{array}$ & $\mathrm{p}$ \\
\hline Left atrial dia & & $3.14 \pm 0.31$ & $2.93 \pm 0.38$ & ${ }^{\mathrm{a}} 0.006 * * *$ \\
\hline Left atrial vol & $\left(\mathrm{ml} / \mathrm{m}^{2}\right)$ & $36 \pm 18$ & $28 \pm 11$ & $\mathrm{p}<0.01$ \\
\hline Left ventricul & olic diameter $(\mathrm{cm})$ & $5.15 \pm 0.44$ & $4.51 \pm 0.32$ & ${ }^{\mathrm{a}} 0.001 * *$ \\
\hline Left ventricul & fraction $(\%)$ & $64.41 \pm 3.92$ & $64.532 \pm 3.22$ & ${ }^{\mathrm{a}} 0.886$ \\
\hline Deceleration & & $157.76 \pm 56.56$ & $115.98 \pm 34.95$ & ${ }^{\mathrm{a}} 0.001 * *$ \\
\hline Septal wall E & & $0.63 \pm 0.13$ & $0.80 \pm 0.09$ & ${ }^{\mathrm{a}} 0.001 * *$ \\
\hline Septal wall A & & $0.85 \pm 0.13$ & $0.47 \pm 0.13$ & ${ }^{\mathrm{a}} 0.001 * *$ \\
\hline E/Em ratio & & $8.02 \pm 2.38$ & $5.97 \pm 1.79$ & ${ }^{\mathrm{a}} 0.001 * *$ \\
\hline \multirow{2}{*}{\multicolumn{2}{|c|}{ İsovolumic relaxation time (msec) }} & $83.28 \pm 18.51$ & $74.43 \pm 22.58$ & ${ }^{\mathrm{a}} 0.052$ \\
\hline & & $\mathrm{n}(\%)$ & $\mathrm{n}(\%)$ & \\
\hline \multirow[t]{4}{*}{ NYHA class } & I & $29(50 \%)$ & $27(90 \%)$ & \multirow{4}{*}{${ }^{\mathrm{b}} 0,001 * *$} \\
\hline & II & $25(43.1 \%)$ & $3(10 \%)$ & \\
\hline & III & $4(6.9 \%)$ & 0 & \\
\hline & IV & 0 & 0 & \\
\hline
\end{tabular}


Tab. 4. Correlation of biochemical characteristics among groups.

\begin{tabular}{lcccc}
\hline & \multicolumn{2}{c}{$\begin{array}{c}\text { Patients with } \\
\text { HFpEF }\end{array}$} & \multicolumn{2}{c}{ Control group } \\
\cline { 2 - 5 } & $\mathrm{r}$ & $\mathrm{p}$ & $\mathrm{r}$ & $\mathrm{p}$ \\
\hline PTH - CRP & 0.114 & 0.396 & 0.200 & 0.289 \\
PTH - NT-proBNP & 0.322 & $0.014^{*}$ & 0.483 & $0.007^{* *}$ \\
PTH - Troponin I & 0.048 & 0.723 & 0.359 & 0.051 \\
PTH - LVEDD & 0.171 & 0.199 & 0.274 & 0.143 \\
PTH - E/Em ratio & -0.086 & 0.523 & 0.047 & 0.805 \\
PTH - age & 0.117 & 0.381 & 0.404 & $0.027^{*}$ \\
PTH - BMI & 0.130 & 0.330 & 0.127 & 0.504 \\
PTH - systolic blood pressure & 0.108 & 0.420 & 0.338 & 0.068 \\
\hline
\end{tabular}

$\mathrm{r}=$ Spearman correlation coefficient, ${ }^{*} \mathrm{p}<0.05, * * \mathrm{p}<0.01, \mathrm{PTH}-$ parathyroid hormone; $\mathrm{CRP}$ - C-reactive protein; NT-proBNP - amino terminal probrain natriuretic peptide; LVEDD - left ventricular end diastolic diameter; BMI - body mass index

LDL levels were significantly higher in patients with HFpEF than those in control group $(\mathrm{p}<0.05)$.

In comparison to control group, left atrium was found to be more enlarged in HFpEF patients $(\mathrm{p}<0.05)$ (Tab. 3). Velocity of early diastolic filling (E) was found to be significantly lower in patients with $\operatorname{HFpEF}(\mathrm{p}<0.01)$. In contrast, velocity of late diastolic filling (A) was significantly higher in patients with $\operatorname{HFpEF}(\mathrm{p}<$ 0.01 ). DT of patients with HFpEF was found to be prolonged compared to control group $(p<0.01)$. IVRT was shorter in control group in a borderline significance compared to patients with HFpEF.

E/E' were detected higher in patients with $\operatorname{HFpEF}(\mathrm{p}<0.01)$. $\mathrm{EF}$ and size of LV were similar in both groups. But LV wall thickness, RWT, and LV mass index were significantly higher in patients with HFpEF compared to control group.

There was no correlation between PTH and CRP, troponin I, LVMI, LV volumes, LV diameters, E/E', age, and BMI in both groups ( $p=$ NS) (Tab. 4). In contrast, there was a statistically significant and strong positive correlation between PTH and NTproBNP levels in all study participants $(\mathrm{r}=0.359$; $\mathrm{p}<0.01)$. Also, there was a statistically significant and positive correlation between PTH and NT-proBNP levels in patients with HFpEF (r $=0.322 ; \mathrm{p}<0.05)$.

There were no differences in PTH measurements according to the presence of CAD in all participants $(p>0.05)$. PTH levels were detected in significantly higher levels in hypertensive HFpEF patients compared to non-hypertensive HFpEF patients $(p<0.05)$. There was no significant difference in PTH levels by the presence of CAD in HFpEF cases ( $p>0.05)$.

\section{Discussion}

PTH has been linked to HF with levels of PTH being predictive for hospitalization in patients with HF (6). PTH promotes intracellular calcium overloading including the mitochondria, which causes destruction of these organelles, ending with cardiomyocyte necrosis and, hence, leakage of troponins.

Secondary hyperparathyroidism (HPTH) was associated with increased mortality and risk of hospitalization $(17,18)$. There are various mechanisms through which high levels of PTH could have harmful effects on the cardiovascular system. In vitro studies have found PTH to have chronotropic (19) and inotropic effects on cardiac muscle (20). Higher PTH may promote specific vascular pathology such as endothelial dysfunction and atherosclerosis (21, 22) that leads to cardiac ischemia and consequent HF. Both experimental and clinical data suggest that PTH has direct detrimental myocardial effects that could lead to increased myocardial susceptibility for cardiac ischemia or increased risk for HF of non-ischemic origin. For instance, myocytes have been shown to be target cells for PTH and higher PTH may induce myocyte hypertrophy, fibrosis, and LVH (23-26). HPTH has been linked with arterial stiffness and hypertension $(19,26)$. PTH exerts a trophic effect on cardiomyocytes with an increase in total cellular mass, while higher serum PTH concentrations are associated with LVH in the general population $(10,27,28)$. Increased PTH level is important as a marker of prognosis. It was found to be related with cardiovascular death in elderly Swedish people (29). High serum PTH levels were strongly associated with advanced HF (6). This association has been explained by the fact that secondary HPTH may contribute to the systemic illness that accompanies advanced HF (30).

Although EF seems to be normal in the patients with HFpEF, pathologic changes in myocardium especially hypertrophy, necrosis and scarring are important. Many previous studies have found that NT-proBNP levels in HFpEF patients are less elevated than in patients with heart failure with reduced EF (31) and that levels tend to be less elevated in patients with chronic heart failure than in those with acute heart failure (30). In contrast to our findings, several recent studies have also demonstrated that a great proportion of HFpEF patients have normal NT-proBNP levels (33-35).

There is a considerable number of studies showing that E/e' correlates well with LV filling pressure and it is regarded as one of the most important non-invasive parameters for estimation of LV filling pressure $(36,37)$. Moreover, E/e' has been shown to be independently predictive of cardiovascular events $(38,39)$.

In our patient group, PTH and NT-proBNP levels were significantly higher than those of controls. The more severe the disease; the more elevated NT-proBNP levels were noted. PHT was found to be related with NT-proBNP levels. Moreover, NT-proBNP is correlated with PTH in our study.

We suggest that PTH could provide complementary information about the severity of HFpEF. PTH together with other markers like troponin and NT-proBNP give valuable data both in the diagnosis and staging of heart failure syndromes.

\section{Conclusion}

We are supposing that our work will be a guide for subsequent studies searching for PTH and related responsible mechanisms causing HFpEF. Our study will also contribute to the prevention of myocardial damage as a primary underlying mechanism of heart failure and more effective treatment of $\mathrm{HFpEF}$, which is an area with limited proven data.

\section{Limitations}

The limitations of the present study include its relatively small sample size and the cross-sectional design. In addition, we 
$442-447$

did not measure serum ionized calcium or magnesium, which are important determinants of PTH secretion. The use of a comprehensive clinical diagnosis as diagnostic standard for HFpEF patients, without an invasive measurement to confirm LV diastolic dysfunction is another drawback of our study. Additionally, LVEF was measured by the biplane Simpson's method in the present study, which might be a poor tool for detecting longitudinal systolic dysfunction. However, previous authors have demonstrated depressed longitudinal strain in HFpEF (40).

\section{References}

1. Yancy CW, Jessup M, Bozkurt B, Butler J, Casey DE Jr, Drazner MH et al. 2013 ACCF/ AHA guideline for the management of heart failure: a report of the American College of Cardiology Foundation/American Heart Association Task Force on Practice Guidelines. J Am Coll Cardiol 2013; 62: 147-239.

2. Owan TE, Hodge DO, Herges RM, Jacobsen SJ, Roger VL, Redfield MM. Trends in prevalence and outcome of heart failure with preserved ejection fraction. N Engl J Med 2006; 355: 251-259.

3. Bhatia RS, Tu JV, Lee DS, Austin PC, Fang J, Haouzi A, Gong Y, Liu PP. Outcome of heart failure with preserved ejection fraction in a population-based study. N Engl J Med 2006; 355: 260-269.

4. ESC guidelines for the diagnosis and treatment of acute and chronic heart failure 2012: The Task Force for the Diagnosis and Treatment of Acute and Chronic Heart Failure 2012 of the European Society of Cardiology. Developed in collaboration with the Heart Failure Association (HFA) of the ESC. Eur J Heart Fail 2012; 14 (8): 803-869.

5. Caruana L, Petrie MC, Davie AP, McMurray JJ. Do patients with suspected heart failure and preserved left ventricular systolic function suffer from 'diastolic heart failure' or from misdiagnosis? A prospective descriptive study. BMJ 2000; 321: 215-218.

6. Altay H, Zorlu A, Binici S, Bilgi M, Yilmaz MB, Colkesen Y et al. Relation of serum parathyroid hormone level to severity of heart failure. Am J Cardiol 2012; 109 (2): 252.

7. Kamalov G, Bhattacharya SK, Weber KT. Congestive heart failure: where homeostasis begets dyshomeostasis. J Cardiovasc Pharmacol 2010; 56 (3): $320-328$.

8. Khouzam RN, Dishmon DA, Farah V, Flax SD, Carbone LD, Weber KT. Secondary hyperparathyroidism in patients with untreated and treated congestive heart failure. Am J Med Sci 2006; 331 (1): 30-34.

9. Schluter KD, Piper HM. Cardiovascular actions of parathyroid hormone and parathyroid hormone-related peptide. Cardiovasc Res 1998; 37: $34-41$.

10. Schluter KD, Piper HM. Trophic effects of catecholamines and parathyroid hormone on adult ventricular cardiomyocytes. Am J Physiol 1992; 263: H1739-46.

11. Harnett JD, Parfrey PS, Griffiths SM, Gault MH, Barre P, Guttmann RD. Left ventricular hypertrophy in end-stage renal disease. Nephron 1988; 48: 107-115.

12. Piovesan A, Molineri N, Casasso F, Emmolo I, Ugliengo G, Cesario F, Borretta G. Left ventricular hypertrophy in primary hyperparathyroidism. Effects of successful parathyroidectomy. Clin Endocrinol (Oxf) 1999; 50: 321-328.

13. Loncar G, Bozic B, Dimkovic S, Prodanovic N, Radojicic Z, Cvorovic V, Putnikovic B, Popovic V. Association of increased parathyroid hormone with neuroendocrine activation and endothelial dysfunction in elderly men with heart failure. J Endocrinol Invest 2011; 34: e78-e85.

14. Baumgartner H, Hung J, Bermejo J, Chambers JB, Evangelista A, Griffin BP, Iung B, Otto CM, Pellikka PA, Quinones M, American Society of Echocardiography, European Association of Echocardiography. Echocardiographic assessment of valve stenosis: EAE/ASE recommendations for clinical practice. J Am Soc Echocardiogr 2009; 22: $1-23$.

15. Nagueh SF, Appleton CP, Gillebert TC, Marino PN, Oh JK, Smiseth OA, Waggoner AD, Flachskampf FA, Pellikka PA, Evangelisa A. Recommendations for the evaluation of left ventricular diastolic function by echocardiography. Eur J Echocardiogr 2009; 10: 165-193.

16. Lang RM, Bierig M, Devereux RB, Flachskampf FA, Foster E, Pellikka PA, Picard MH, Roman MJ, Seward J, Shanewise J, Solomon S, Spencer KT, St John Sutton M, Stewart W. Recommendations for chamber quantification. Eur J Echocardiogr 2006; 7: 79-108.

17. Johnson DW, Craven AM, Isbel NM. Modification of cardiovascular risk in hemodialysis patients: an evidence-based review. Hemodial Int 2007; 11: 1-14.

18. Horl WH. The clinical consequences of secondary hyperparathyroidism: focus on clinical outcomes. Nephrol Dial Transplant 2004; 19 (Suppl 5): V2-V8.

19. Bogin E, Massry SG, Harary I. Effect of parathyroid hormone on rat heart cells. J Clin Invest 1981; 67: 1215-1227.

20. Ogino K, Burkhoff D, Bilezikian JP. The hemodynamic basis for the cardiac effects of parathyroid hormone (PTH) and PTH-related protein. Endocrinology 1995; 136: 3024-3030.

21. Perkovic V, Hewitson TD, Kelynack KJ, Martic M, Tait MG, Becker GJ. Parathyroid hormone has a prosclerotic effect on vascular smooth muscle cells. Kidney Blood Press Res 2003; 26: 27-33.

22. Rashid G, Bernheim J, Green J, Benchetrit S. Parathyroid hormone stimulates endothelial expression of atherosclerotic parameters through protein kinase pathways. Am J Physiol Renal Physiol 2007; 292: F1215F1218.

23. Amann K, Ritz E, Wiest G, Klaus G, Mall G. A role of parathyroid hormone for the activation of cardiac fibroblasts in uremia. J Am Soc Nephrol 1994; 4: 1814-1819.

24. Liu X, Xie R, Liu S. Rat parathyroid hormone 1-34 signals through the MEK/ERK pathway to induce cardiac hypertrophy. J Int Med Res 2008; 36: 942-950.

25. Nilsson IL, $\mathbf{A}^{\circ}$ berg J, Rastad J, Lind L. Left ventricular systolic and diastolic function and exercise testing in primary hyperparathyroidismeffects of parathyroidectomy. Surgery 2000; 128: 895-902.

26. Jorde R, Sundsfjord J, Haug E, Bonaa KH. Relation between low calcium intake, parathyroid hormone, and blood pressure. Hypertension 2000; 35: 1154-1159.

27. Saleh FN, Schirmer H, Sundsfjord J, Jorde R. Parathyroid hormone and left ventricular hypertrophy. Eur Heart J 2003; 24: 2054-2060.

28. Kestenbaum B, Katz R, de Boer Iet al. Vitamin D, parathyroid hormone, and cardiovascular events among older adults. J Am Coll Cardiol 2011; 58 (14): 1433-1441.

29. Hagström E, Hellman P, Larsson TE, Ingelsson E, Berglund L, Sundström J, Melhus H, Held C, Lind L, Michaëlsson K, Arnlöv J. Plasma Parathyroid Hormone and the Risk of Cardiovascular Mortality in the Community. Circulation 2009; 119: 2765-2771. 
30. Alsafwah S, Laguardia SP, Arroyo M, Dockery BK, Bhattacharya SK, Ahokas RA et al. Congestive heart failure is a systemic illness: a role for minerals and micronutrients. Clin Med Res 2007; 5 (4): 238-243.

31. Barasch E, Gottdiener JS, Aurigemma G, Kitzman DW, Han J, Kop WJ, Tracy RP. Association between elevated fibrosis markers and heart failure in the elderly: the cardiovascular health study. Circ Heart Fail 2009; 2: 303-310.

32. Maisel A, Mueller C, Adams K Jr., Anker SD, Aspromonte N, Cleland JG, Cohen-Solal A, Dahlstrom U, DeMaria A, Di Somma S, Filippatos GS, Fonarow GC, Jourdain P, Komajda M, Liu PP, McDonagh T, McDonald K, Mebazaa A, Nieminen MS, Peacock WF, Tubaro M, Valle R, Vanderhyden M, Yancy CW, Zannad F, Braunwald E. State of the art: using natriuretic peptide levels in clinical practice. Eur J Heart Fail 2008; 10: 824-839.

33. Borlaug BA, Nishimura RA, Sorajja P, Lam CS, Redfield MM. Exercise hemodynamics enhance diagnosis of early heart failure with preserved ejection fraction. Circ Heart Fail 2010; 3: 588-595.

34. Ingle L, Cleland JG, Clark AL. Perception of symptoms is out of proportion to cardiac pathology in patients with 'diastolic heart failure'. Heart 2008; 94: 748-753.

35. Penicka M, Bartunek J, Trakalova H, Hrabakova H, Maruskova M, Karasek J, Kocka V. Heart failure with preserved ejection fraction in outpatients with unexplained dyspnea: a pressure-volume loop analysis. J Am Coll Cardiol 2010; 55: 1701-1710.
36. Nagueh SF, Middleton KJ, Kopelen HA, Zoghbi WA, Quinones MA. Doppler tissue imaging: a noninvasive technique for evaluation of left ventricular relaxation and estimation of filling pressures. J Am Coll Cardiol 1997; 30: 1527-1533.

37. Ommen SR, Nishimura RA, Appleton CP, Miller FA, Oh JK, Redfield MM, Tajik AJ. Clinical utility of Doppler echocardiography and tissue Doppler imaging in the estimation of left ventricular filling pressures: a comparative simultaneous Doppler-catheterization study. Circulation 2000; 102: 1788-1794.

38. Okura H, Kubo T, Asawa K, Toda I, Yoshiyama M, Yoshikawa J, Yoshida K. Elevated E/E' predicts prognosis in congestive heart failure patients with preserved systolic function. Circ J 2009; 73: 86-91.

39. Sharp AS, Tapp RJ, Thom SA, Francis DP, Hughes AD, Stanton AV, Zambanini A, O'Brien E, Chaturvedi N, Lyons S, Byrd S, Poulter NR, Sever PS, Mayet J. Tissue Doppler E/E' ratio is a powerful predictor of primary cardiac events in a hypertensive population: an ASCOT substudy. Eur Heart J 2010; 31: 747-752.

40. Wang J, Khoury DS, Yue Y, Torre-Amione G, Nagueh SF. Preserved left ventricular twist and circumferential deformation, but depressed longitudinal and radial deformation in patients with diastolic heart failure. Eur Heart J 2008; 29: 1283-1289.

Received February 2, 2016. Accepted February 12, 2016. 